\title{
Quality and Safety Management in Building Constructions
}

\author{
Pranay R. Adsire ${ }^{1}$, Dr. Mrs. Sushma S. Kulkarni ${ }^{2}$ \\ ${ }^{I}$ Department of Civil Engineering, Rajarambapu Institute of Technology, Rajaramnagar, India \\ ${ }^{2}$ Department of Civil Engineering, Rajarambapu Institute of Technology, Rajaramnagar, India
}

\begin{abstract}
In construction of buildings, materials consume more than 60\% of the total cost of construction. To increase the life of buildings quality of material should be good. By using proper quality of material construction life span can be increased. In India, due to improper safety management and negligence towards safety many people loose their life every year. Safety is very important parameter in construction industry. To avoid such accidents on construction site proper safety should be provided and also worker should know the importance of safety at the time of work on high rise buildings. The purpose of this study is to check the quality of concrete and its ingredients. For the material check a questionnaire survey is made from that survey quality of material is assessed very easily. The Safety, health and environment issues can be easily handle using suggestions given in this paper.
\end{abstract}

Keywords: Quality, Concrete, Statistical Analysis, mix design, safety, health, environment.

\section{Introduction}

India is a developing country and most developments are going on in construction industry. India has maximum manpower to utilize as optional to the machine work to promote employment. Over 3 crore people are working in construction industry of India. Across the world, it is felt that quality and safety in construction industry is matter of concern. In India this is among one of the most important issues.

Quality of material is major problem faced on every residential as well as commercial buildings. To maintain the quality of material various tests are performed on material. Not only quality, safety is also major problem faced on construction site. In India safety of worker is not taken as major problem due to which many worker loose their life due to lack of safety on construction site. The main purpose of this study is to maintain quality of work and to reduce accident on construction site.

\section{Methodology}

The study comprises of detailed inspection of quality of concrete and its ingredients in building construction. The research consist of the quality of concrete ingredients, checklist for the quality of concrete material on RMC plant.

\subsection{Material Testing:}

\section{Study Area}

On RMC plant daily material testing is done. In that crushed sand, coarse/fine aggregate is checked daily and their results decide the acceptance of that material. Following are the some tests done on material:

Crushed sand

Sieve Analysis

Silt Content

Moisture Correction

Coarse / fine aggregate

Sieve Analysis.

\subsection{Acceptance Criteria for Material}

\begin{tabular}{|l|l|l|l|l|}
\hline Sr No. & Test & Result & Correction & Remark \\
\hline 1 & Moisture Correction & $0-3$ & \pm 0.2 & Ok \\
\hline 2 & Sieve Analysis $(10 \mathrm{~mm})$ & $2.3-3.1$ & \pm 0.5 & Ok \\
\hline 3 & Sieve Analysis $(20 \mathrm{~mm})$ & $2.6-3.2$ & \pm 0.5 & Ok \\
\hline 4 & Fineness Content in Cement & $10 \%$ & \pm 1 & Ok \\
\hline
\end{tabular}

\subsection{Effect of Moisture Correction on Slump}

Moisture correction directly affect on fresh concrete. As moisture increase in crushed sand, fine aggregate and coarse aggregate, slump is also increases. The graph below this shows the relation between moisture and slump. 


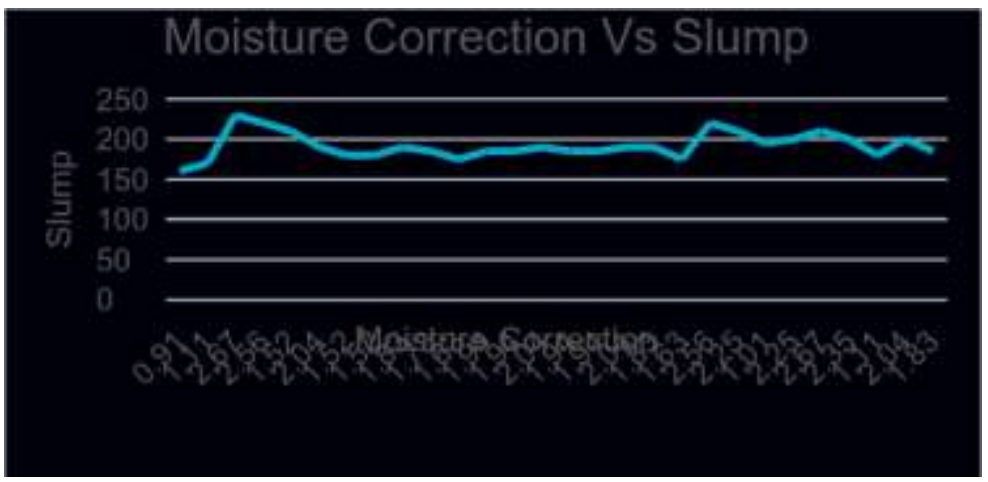

\subsection{Concrete Mix}

Concrete mix is prepared in RMC plant. The capacity of RMC plant is $1 \mathrm{~m} 3$. The RMC plant is fully automatic. The capacity of aggregate weigher is $2500 \mathrm{~kg}$. The maximum weight used for calibration of cement + fly ash is $500 \mathrm{~kg}$ and the capacity of admixture weigher is $10 \mathrm{~kg}$. The RMC plant is calibrated once in three month.

The trial mix is prepared on batch mixer. For trail is prepared for $1 \mathrm{~m} 3$ of material. The quantity of material is calculated for $1 \mathrm{~m} 3$. If the concrete trail mix is gives the satisfied result then this mix can be used in future work.

\subsection{Transportation:}

Concrete transported form RMC plant to site by Transit mixer. The capacity of transit mixer is $6 \mathrm{~m} 3$. In RMC plant, to fill one transit mixer 8 min time required. For Transporting of concrete from RMC to site 20 min time required and to unload the concrete on site an average 30- 45 min required as per side condition. Within 3 hrs. Concrete in transit mixer should be place on site, after 3 hrs. That concrete is directly rejected.

\subsection{Concrete Placing Method:}

Properly mixed concrete having good workability at the time of placement may lose some or all of its desirable characteristics due to mishandling at the job site. Concrete can segregate in the same way coarse aggregate could segregate during stockpiling operations. The "free fall" of concrete (outside the limits of a spout or chute) should not exceed $1.2 \mathrm{~m}$ (4 ft.). Always place concrete as near as possible to its final position in the completed structure.

\subsubsection{Buckets:}

Check concrete buckets for accumulation of dry and hardened concrete and have the material removed prior to use. Control segregation by minimizing the fall of concrete when charging the concrete bucket. Move the bucket during discharge into the forms to prevent the formation of concrete piles. The capacity of bucket is $0.3 \mathrm{~m}^{3}$

\subsubsection{Chutes and Belts}

Divert the fall of concrete discharged from the ends of chutes and belts by a baffle. Unrestricted fall permits the coarse portion of the batch to separate and carry to the front end of the discharge while the soft or mortar portion of the batch flows under and to the back of the discharge.

When concrete is discharged from a ready-mix concrete truck, move the chute back and forth to reduce segregation. Do not permit the concrete to build up in piles if the concrete is spouted onto the ground as in curb and gutter or pavement construction. Spread by moving the chute in as large an arc as possible within the form area. Once the concrete is slightly above the form elevation, move the truck to a new location and repeat the operation. Move concrete from high to low areas by shovelling; never move concrete with a vibrator.

\section{Slump Cone Test:-}

This slump cone test is carried on fresh concrete to check the workability of concrete. Slump cone test carried out twice on fresh concrete first is on the RMC plant and second is on the site before placing of concrete. On RMC plant the slump of fresh concrete should be above $180 \mathrm{~mm}$ and on site it should be above $150 \mathrm{~mm}$.

\subsubsection{Pumping Concrete}

Concrete has a tendency to become stiffer or lose more slump and entrained air from pumping than with other placement methods. This is partly due to additional heat caused by friction as the concrete is forced through the pipe. You may need to increase the slump and entrained air content of the concrete from the 
specified range for this reason to assure that it meets Specification. This type of concrete placing method is used for mass concreting (slab). The capacity of pump is about 1400 to $1800 \mathrm{hp}$. Normally $1400 \mathrm{hp} \mathrm{pump} \mathrm{is} \mathrm{used} \mathrm{for}$ concreting up to 15th floor. Over the 15th floor $1800 \mathrm{hp}$ pump is used for pumping the concrete. Pipes are attached to the pump for delivery of concrete at the right place.

\subsection{Compaction Method}

Vibration of concrete makes it more workable and will make relatively dry concrete behave like concrete having a higher slump. Internal vibration is performed using a long, slender, vibrating cylinder that is projected into the concrete. The ratio of diameter to length of the head, the weight and speed of vibration for internal vibrations, will vary with the workability of the concrete and the type of section constructed. In the construction of large heavy sections, the concrete used may appear harsh and stiff. The vibrating head for this work is shorter with a larger diameter up to $75 \mathrm{~mm}$ ( 3 in.). On thin sections, the concrete is more plastic (having both a lower coarse aggregate content and a smaller size aggregate), and a vibrator with a longer head and a smaller diameter of 19 to $32 \mathrm{~mm}$ ( $3 / 4$ to $11 / 4 \mathrm{in}$.) is used.

\subsection{Curing Concrete}

One of the most important steps in concrete paving is the method used to prevent loss of mix water. Moisture is maintained in the concrete for the following reasons:

- Facilitate hydration

- Prevent surface (map) cracking

- Allow the concrete to reach its design strength

The cure is applied when the finishing of an area is complete. If the texturing went well, it is time to cure. Begin cure application when the original sheen has nearly disappeared. When weather conditions exist that make the decision when to spray difficult, it is better to spray too early rather than too late.

A minimum curing period of at least 3 days at about 15 to $20^{\circ} \mathrm{C}\left(60\right.$ to $\left.70^{\circ} \mathrm{F}\right)$ is necessary to give the concrete an ability to attain its potential strength. For adequate curing, the concrete must remain moist and have favorable temperature conditions.

\subsection{Testing on Concrete}

Concrete testing is done in two parts i.e. fresh concrete and harden concrete. Concrete is tested for workability and strength. Workability check on fresh concrete and the compressive strength is done on hardened concrete.

\subsubsection{Fresh Concrete \\ Slump Cone Test}

This slump cone test is carried on fresh concrete to check the workability of concrete. Slump cone test carried out twice on fresh concrete first is on the RMC plant and second is on the site before placing of concrete. On RMC plant the slump of fresh concrete should be above $180 \mathrm{~mm}$ and on site it should be above $150 \mathrm{~mm}$.

\subsubsection{Harden Concrete}

\section{Compressive Strength Test}

This compressive strength test is carried on harden concrete to check the strength of harden concrete.

For this testing cube are casted on RMC and on site total 12 cubes are casted. Strength should be as below-

$\begin{array}{lll}\text { For, } \quad 3 \text { days } & 45 \% \text { strength } \\ 7 \text { days } & 67 \% \text { strength } \\ 28 \text { days } & 100 \% \text { strength }\end{array}$

\subsection{Relation between W/C Ratio and Compressive Strength of Concrete}

Water cement ratio is the major factor which directly effect on strength of concrete. To find the relation between w/c ratio and compressive strength of concrete first calculate the limit for the graph. Limit are calculated from formulas of walter shewhart control limit theory.

For Control Limit $=$ Average of compressive strength

Upper control limit $=$ Avg. $+3 *$ std. deviation

Lower control limit $=$ Avg. $-3 *$ std. deviation

Upper waring limit $=$ Avg. $+2 *$ std. deviation

Lower waring limit $=$ Avg. $-2 *$ std. deviation

This limit are calculated to know the upper and lower limit up to which compressive strength may vary. The value of samples below lower control limit are rejected. Form this formulas the limit are calculated as below 
Standard Deviation $=\quad 10.81$

Control Limit $=36.58$

Upper control limit $=\quad 58.02$

Lower control limit $=14.96$

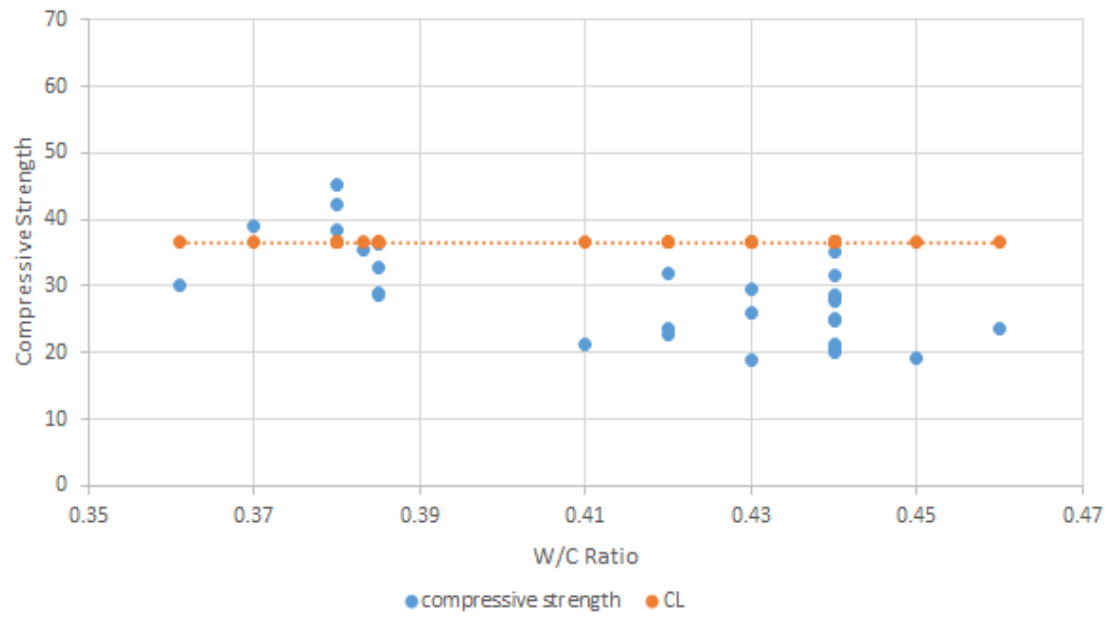

Compressive Strength vs W/C Ratio

In above graph, it observed that compressive strength of concrete cube decreases with increase in water cement ratio. However, compressive strength increases with age of concrete cubes. Maximum compressive strength obtain at $0.38 \mathrm{w} / \mathrm{c}$ ratio. As w/c ratio increases the value of compressive strength obtain below the control line limit.

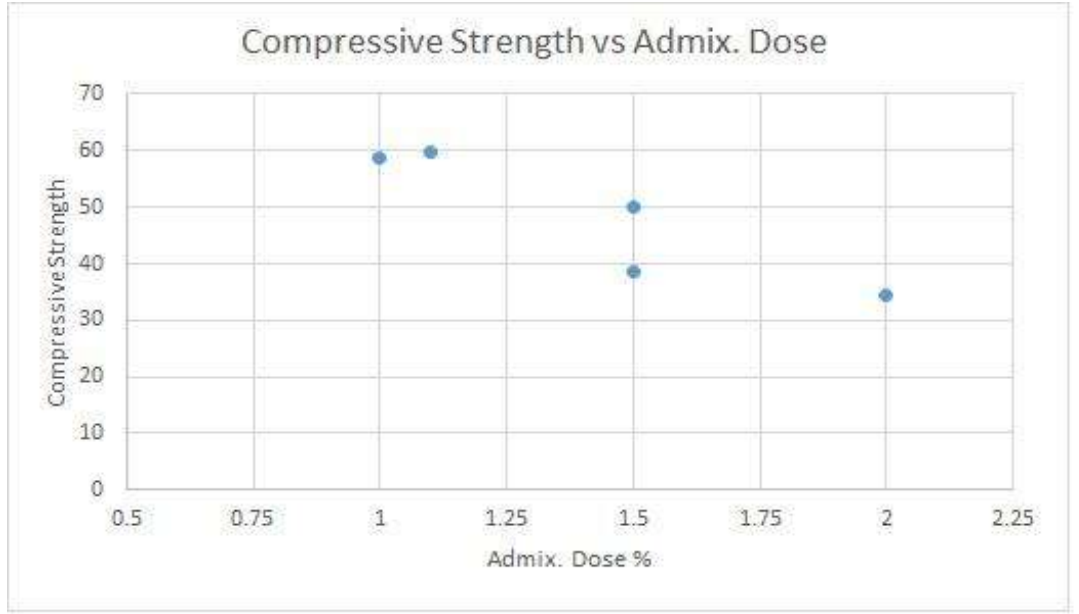

Compressive Strength vs Admix. Dose \%

In above graph, admixture dose percentage change from $1 \%$ to $2 \%$ and w/c ratio is constant i.e. 0.38 . It observed that as admixture dose increases in concrete the compressive strength increases at some percentage but after specific percentage of admixture dose compressive strength of concrete decreases. As admixture dose increase $1 \%$ to $1.1 \%$ the value of compressive strength increases but as admixture dose increase $1.5 \%$ to $2 \%$, the value of compressive strength decreases.

\subsection{Safety and Health Provisions on Site}

Safety is the state of being "safe". the condition of being protected against physical, social, spiritual, financial, political, emotional, occupational, psychological, educational or other types or consequences of failure, damage, error, accident, harm or any other event which could be considered non-desirable.

Company made basic safety provisions for worker, engineers, and managers on site. Worker should wear helmet, safety shoes, and safety belt at working place. Safety engineer should wear safety shoes, reflection jacket, and helmet at working place. 


\subsection{Acts for safety management on site}

Indian government, state government and companies have made some basic laws for worker for safe condition on site. Following are the some important laws by them

- Labour Act - In this labour act, the wages, number of hours of work, social securities and facilities provide to worker is given.

- The Dock Workers Act, 1986 - In this dock worker act, the provision of companies towards workers health and safety is given.

- The Child Labour (Prohibition and Regulation) Act, 1986

- The Personal Injuries (Compensation Insurance) Act, 1963

\subsection{Reasons for lack of safety on site}

Government and companies have their laws for safety condition on site, however accidents occurs on site due to many reasons. Following are the main reasons seen on sites

- Negligence of worker towards safety.

- Improper communication between workers and safety officers.

- Safety officers not taking any action on worker if they are not using any safety precaution on site.

- Company not providing safety shoes, gloves to the worker.

- Safety officers take daily safety check up on site but they doesn't take any action on that.

\subsection{Solution for effective use of safety management on site}

In this study of health and safety management, the author study the recent health and safety measures on site and give the effective plan for safety management as follows

- Worker who doesn't fallows the safety rules on site , firstly safety engineer gives three warnings to them after that they should penalties and they doesn't allow to work on site.

- Training should provide to freshly or newly joining worker. There should be two types of training for them

1. Tool box Talk

2. Enduction Training

- Checklist should provide for all type of work.

- Fist aid box should be provide on-site.

- Housekeeping is done properly.

- At height of work, three safety net should be provided. First at first floor, second at below the work place floor and third at work place floor at an angle $45^{\circ}$.

\subsection{Types of accidents and its causes}

In this study, we have analysied the last three years data of number of accidents and its causes. These accidents are classified into two types 1. Major accidents 2. Minor accidents. In major case deaths, permanent body part injury etc. and in minor case fist aid case, temporary body injuries etc. are recorded. Based on these accidents causes of accidents classified as 1.Unsafe act 2. Unsafe condition 3. Beyond the human control.

This study related with the last three years data of safety on Amanora Town Park, Pune. The data collected from the site and this data analysied for the further work.in this work

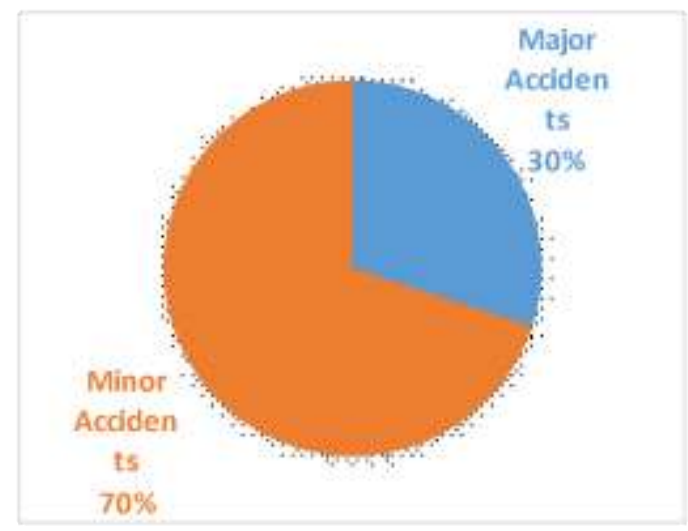

Types of Accidents

The above figure shows the types of accidents occurs in last three years. In last three years $30 \%$ major accidents occurs on site in that 1 was death and others are permanent body injuries and $70 \%$ accidents are minor in this accidents mainly fist aids accidents occurs. 


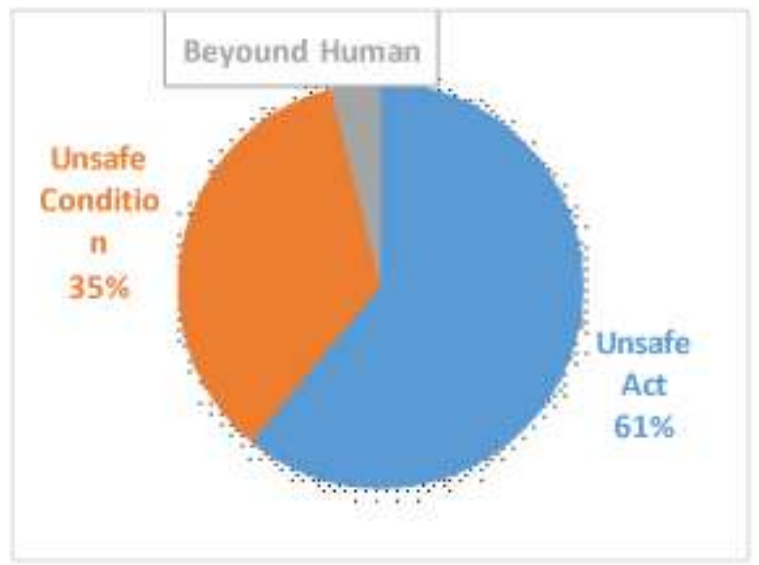

Causes of Accidents

The above figure shows the causes of accidents occurs on site, $61 \%$ accidents occurs due to unsafe act on site i.e. operating without permission, using unsafe tools and $35 \%$ accidents occurs due to unsafe conditions on site i.e. poor housekeeping, improper barricading, improper electrical connection and $4 \%$ accidents occurs due to beyond human control i.e. atmospheric condition

\section{Conclusion}

Moisture correction plays important role in concrete mix. On RMC plant moisture correction taken thrice in a day. Moisture correction directly affects on slump of concrete. As moisture increases0.91 to 2.67, slump increase 150 to $230 \mathrm{~mm}$.

Statistical analysis is done for monitor and control the compressive strength of concrete. The value of compressive strength is beyond the control limit at $0.38 \mathrm{w} / \mathrm{c}$ ratio. As w/c ratio exceed 0.38 , the value of compressive strength decreases. Which is below the control limit.

From the site survey, we analyzed the total number of accidents. These incidents are divided into two categories -major and minors. In major cases of permanent death, damage to parts of the body, and other fatal and mild cases of emergency situation, temporary body parts damage.

Total major accidents are 9 no. and minor 18 no. based on questionnaire survey and interviewing safety engineers. Major accidents occurs $30 \%$ and Minor accidents occurs $70 \%$ on this site.

Based on number of accident and data acquisition, mainly due to insecurity incidents. They are listed as the cause of the accident situation -unsafe $61 \%, 35 \%$ of unsafe behaviour, beyond human control only $4 \%$.

\section{References}

[1]. N. M. Cachadinha, (2009), "Implementing Quality Management Systems in Small and Medium Construction Companies", American society of civil engineering, 2009.9:32-39.

[2]. W. B. Ledbetter, z Fellow, (1994), "Quality Performance On Successful Project", American society of civil engineering, 120:34-46.

[3]. Debashis Das, Abhijit Chatterjee, (2013), "A Proposed Statistical Procedure for Assessment of Strength of Concrete from Low Sample Size Using Monte Carlo Simulation”, International Journal of Engineering Science and Innovative Technology (IJESIT) Volume 2, Issue 4, July 2013

[4]. Phoon, K. K., Wee, T. H., and Loi, C.S, (1999), "Development of statistical quality assurance criterion for concrete using ultrasonic pulse velocity method", ACI Materials Journal., vol. 96, no.5, pp.568-574, 1999.

[5]. Burak Felekoglu, Selcuk Turkel, Bulent Baradan, (2007), "Effect of water/cement ratio on the fresh and hardened properties of selfcompacting concrete", Elsevier Journal, Vol. 42, 1795-1802, 2007

[6]. Rohit Laxman Tudayekar, Sushma Shekhar Kulkarni, (2014), "Safety and Emergency Management on Construction Sites", Current Trends in Technology and Science, ISSN: 2279- 0535,Volume: 3, Issue: 4.

[7]. Venumadhav Yemul, Milind Darade, (2014), "Occupational Safety and Health in Construction Industry for High Rise Building", International Journal of Innovative Science, Engineering \& Technology, Vol. 1 Issue 10.

[8]. Mohamed Alhajeri, (September 2011), "Health and Safety in the Construction Industry", Third International World of Construction Project Management 2011, PP 18-175.

[9]. Ganapathi Bhat, Y.S.Sidde Gowda, (2013), "Safety Management System of Construction Activities in UAE Infrastructure Project", International journal of Engineering, ISSN: 2249 - 8958, Vol-2, Issue-6. 